\title{
Removal of selected pesticides by nano zero-valent iron
}

\author{
Karol Šimkovič, Ján Derco, Mária Valičková \\ Faculty of Chemical and Food Technology, Slovak University of Technology, \\ Radlinského 9, 81237 Bratislava, Slovakia \\ karol.simkovic@stuba.sk
}

\begin{abstract}
This paper is focused on the possibility of using iron nanoparticles (nZVI - nano zero-valent iron) to remove selected specific synthetic substances, such as hexachlorobutadiene, pentachlorobenzene, hexachlorobenzene, lindane and heptachlor. Experimental measurements were performed in order to evaluate the effectiveness of the removal of substances and their specific removal rate. Evaluation of the results shows that nanoiron NANOFER 25 is a convenient reactant for the removal of heptachlor, lindane and hexachlorobenzene; while for pentachlorbenzene and hexachlorobutadiene removal, longer contact times are necessary to achieve significant removal efficiencies.
\end{abstract}

Keywords: nanoiron particles, nZVI, organochlorinated substances, persistent substances, priority substances, zero-valent iron

\section{Introduction}

Quality drinking water is one of the requisites for a healthy human population. However, growing industrialization and extensive use of chemicals have increased the amount of unwanted pollutants in sources of drinking water in countries all over the world. Priority substances were discharged to the aquatic system (groundwater and surface water) as waste products from industrial production or from substances known as insecticides, herbicides and fungicides which have been applied in forestry and agriculture for a long time. The amount of potentially hazardous substances entering the ecosystem is increasing every day. All priority substances monitored in this study are also known as organochlorinated pesticides (OCP) which are potentially carcinogenic, persistent and toxic. They can be absorbed by plants, animals and also people. Humans and animals are exposed to them mostly through their diet, occupationally or prenatally. Over $90 \%$ of exposure comes from animal products due to bioaccumulation in fat tissues and through the food chain (Ritter et al., 2007). Contamination of soils and groundwater by chlorinated pesticides has been a worldwide environmental challenge and cost effective remediation technologies have been sought for decades.

Nanotechnology seems to be the answer to the search for an efficient, economic and ecologically friendly method to solve or reduce this problem. The use of nanotechnology and nanomaterials is very extensive. This technology applies particles with the dimensions of roughly $1-100 \mathrm{~nm}$ and has already found applications in many areas of daily life, e.g. in electronics, engineering, health, chemical industry as well as optical, automotive, cosmetics and military industries. Particles of nZVI can be used in on site reactors (e.g. pump-and-treat systems) or in situ applications (direct push injections, recirculation by injection/extraction wells, pneumatic fracturing (Grieger et al., 2010). Due to their nano-sized dimensions, nZVI particles have significantly larger available reactive surface areas (e.g. up to four orders of magnitude (Macé et al., 2006) compared to larger iron particles, which subsequently enhances contaminant degradation reactions (Chang and Kang, 2009; Lin et al., 2008). The core of iron nanoparticles (core-shell structure) consists of zero-valent iron (ca. $85 \%$ ) while the shell consists mostly of iron oxides and oxyhydroxides. Thus, iron nanoparticles exhibit characteristics of both a sorbent and a reducing agent (Černík et al., 2010).

The use of nZVI is a very promising method for removing not only organochlorinated pesticides but also many other types of micropollutants. The aim of this research was to study the potential of nZVI particles to improve the removal process of selected specific synthetic substances from water.

\section{Materials and methods}

NANOFER 25 nanoparticles used in this work had the average grain size of $50 \mathrm{~nm}$. The particle size is one of the main and most important factors in this technology. Suspension of NANOFER 25 nZVI particles produced by NANOIRON s.r.o., Czech Republic, contains $14-18$ wt. \% of Fe, 2-6 \% of $\mathrm{Fe}_{3} \mathrm{O}_{4}, 0-1 \%$ of carbon and $80 \%$ of water. Specific surface area of these nanoparticles is larger than $25 \mathrm{~m}^{2} / \mathrm{g}$ (www.nanoiron.cz). Experiments were 
performed with model wastewater containing chlorinated pesticides, i.e. hexachlorobenzene (HCHB), hexachlorobutadiene (HCHBD), pentachlorobenzene (PCHB), (1r,2R,3S,4r,5R,6S)-1,2,3,4,5,6hexachlorocyclohexane (common name lindane, $\gamma$-HCH; abbreviation LIN) and 1,4,5,6,7,8,8-heptachloro-3a,4,7,7a-tetrahydro-4,7-methano-1H-indene (common name heptachlor, abbreviation $\mathrm{HCH}$ ); first three of these compounds are specified as priority hazardous substances (EU, 2000; 2008) while all pesticides except for HCHBD are listed in the Stockholm Convention of Persistent Organic Pollutants (Stockholm Convention, 2001; 2009). Experiments were carried out in a mechanically stirred reactor under laboratory conditions. The measurements were performed in a $2000 \mathrm{ml}$ reactor containing $200 \mathrm{ml}$ of NANOFER 25 and $1000 \mathrm{ml}$ of model wastewater. A mechanically stirred reactor was used to homogenize the reaction mixture of water and nanoscale zero-valent iron (nZVI) and to perform the experiments. Nanofer suspension used in the experiments was added into the reactor at the beginning of the process.

\section{Analytical methods}

Quantification of organochlorinated pesticides in wastewater was achieved by a gas chromatographic method after liquid-liquid extraction. As the organic solvent for HPLC, n-hexane 96 \% p.a. (Analytika, s.r.o.) was used. The extract was analyzed by gas chromatography employing a micro-electron capture detector (Agilent Technologies 7890A GC Systems). All parent organochlorinated compounds used for the preparation of synthetic wastewater and standard stock solutions were purchased from
Supelco Co (Member of Sigma-Aldrich Group, USA) in high quality.

\section{Results and discussion}

Determination of the concentration of individual pesticides was performed after 4, 6, 8, 9 and 24 hours. The chosen initial concentration of pollutants was $107 \mathrm{ng} / \mathrm{l}$ for HCHBD, $49670 \mathrm{ng} / \mathrm{l}$ for PCHB $\mathrm{ng} / 1,5573 \mathrm{ng} / \mathrm{l}$ for HCHB, $5980 \mathrm{ng} / \mathrm{l}$ for LIN and $15613 \mathrm{ng} / 1$ for HCH. Fig. 1 shows the removal efficiency of pesticides during their reaction with zero-valent iron nanoparticles (nZVI). The highest treatment efficiencies were observed for LIN, $\mathrm{HCHB}$ and $\mathrm{HCH}$, within about $4 \mathrm{~h}$. After this time, the highest removal efficiency was achieved for lindane. The obtained data show that after 24 hours of the experiment, iron had reduced more than $97 \%$ of all three substances. Final removal efficiencies of $99 \%$ and $97 \%$, respectively, were observed for LIN and HCHB. Obviously, HCH was completely degraded / removed from model wastewater.

Removal of the remaining two studied pesticides by nZVI is presented in Fig. 2. Lower removal efficiency (about $25 \%$ ) was observed for HCHBD after $4 \mathrm{~h}$ of the process. At the same time, removal efficiency of PCHB reached only about $17 \%$. The removal efficiency of HCHBD reached the highest value $(73 \%)$ after $8 \mathrm{~h}$ of the process, and the maximum removal efficiency of $\mathrm{PCHB}$ was obtained after 24 h (85\%).

Time dependencies of volumetric removal rates for individual pollutants and processes are shown in Fig. 3. The highest removal rates of all pollutants except for HCHBD were observed after $4 \mathrm{~h}$ of the treatment. For HCHBD, the same removal rate was

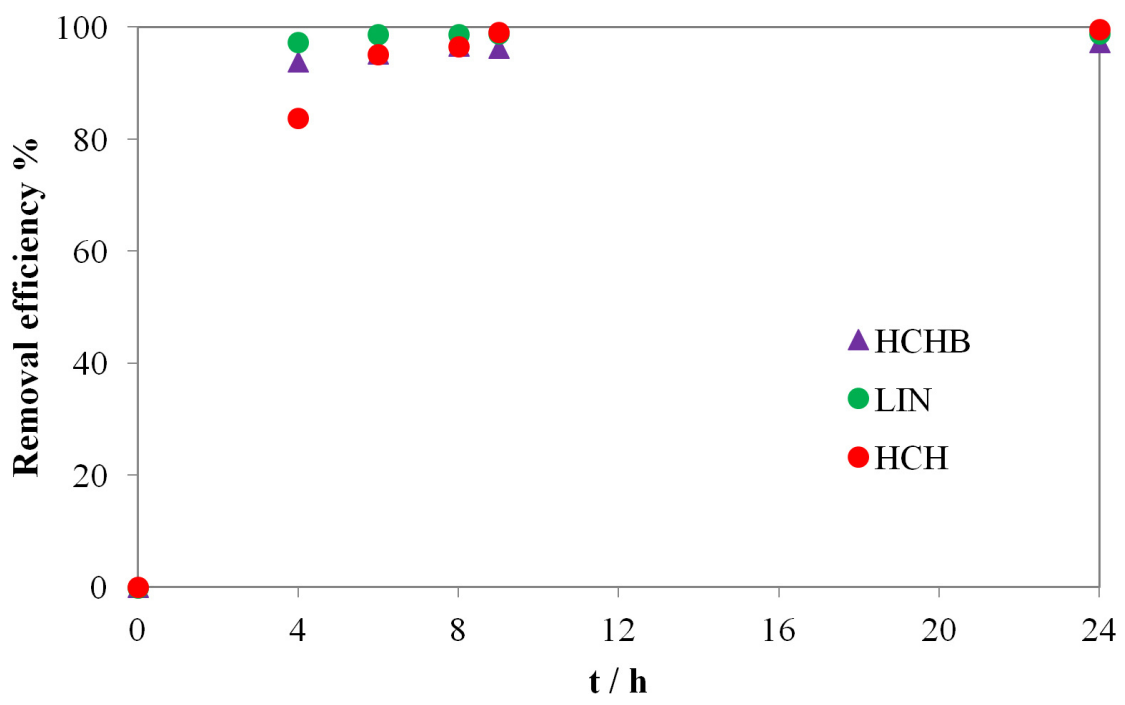

Fig. 1. Removal efficiency of organochlorinated compounds with nZVI. 


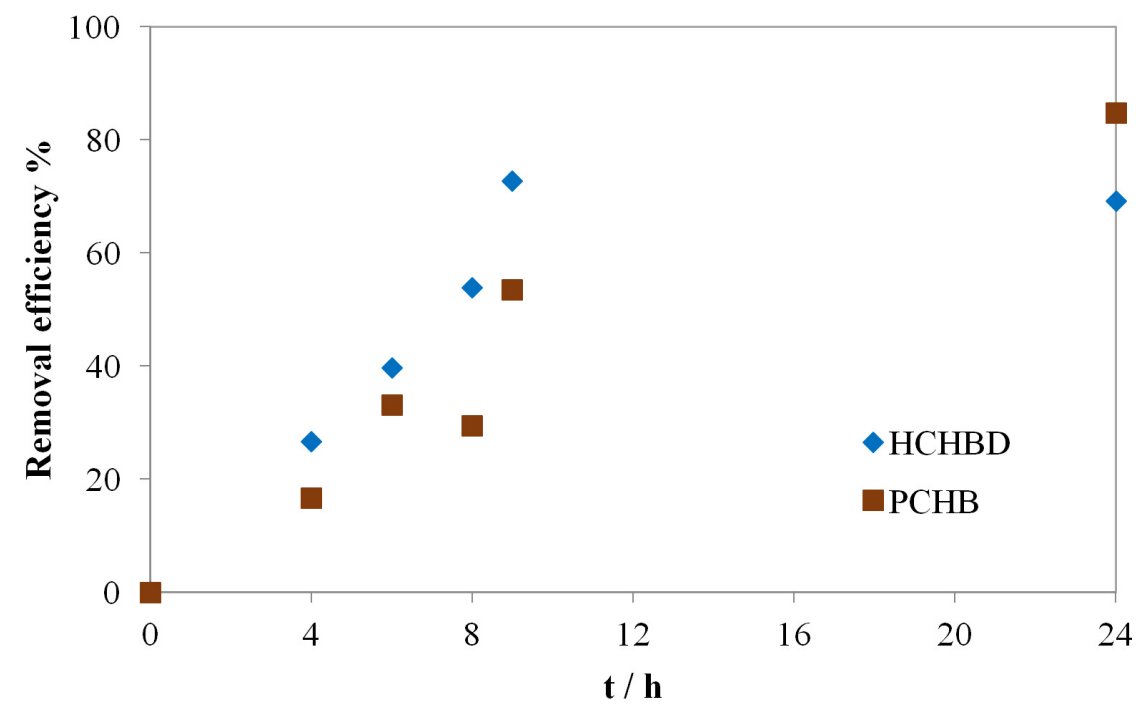

Fig. 2. Removal efficiency of organochlorinated compounds with nZVI.

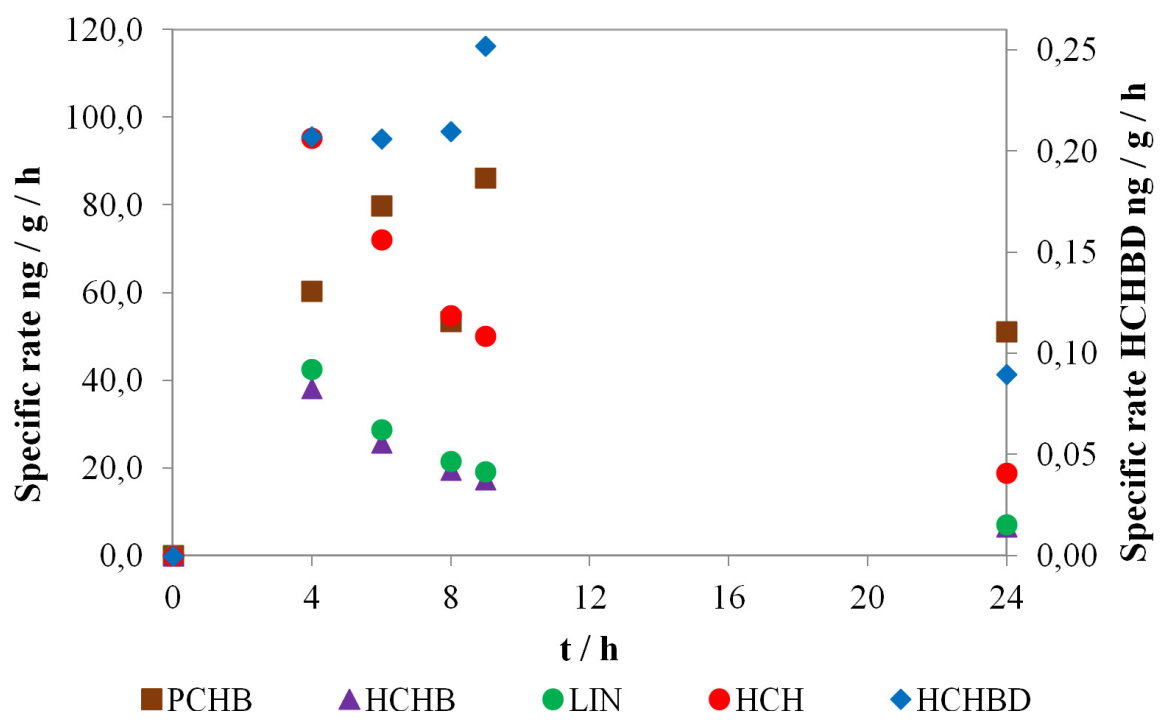

Fig. 3. Removal rates of organochlorine compounds with nZVI (HCHBD - right Y axis; other pollutants - left $\mathrm{Y}$ axis).

observed after $9 \mathrm{~h}$ of the process. As shown in Figs. $1-3$, the highest specific removal rate corresponds to the maximum concentration decrease. Heptachlor $\mathrm{HCH}$ showed the highest affinity to nZVI of $95 \mathrm{ng} \cdot \mathrm{g}^{-1} \cdot \mathrm{h}^{-1}$. Also, higher affinity to $\mathrm{nZVI}$ was observed in case of PCHB $\left(60 \mathrm{ng} \cdot \mathrm{g}^{-1} \cdot \mathrm{h}^{-1}\right)$. HCHBD showed the lowest specific removal rate; lower by about three orders of magnitude compared to the pesticides studied.

\section{Conclusion}

The commercial suspension of Nanofer 25 nZVI particles was used in the removal of selected organochlorinated pesticides, showing very promising results in regard to removal efficiency of the major- ity of substances. The highest removal efficiencies were observed for HCH, LIN and HCHB, already within about $4 \mathrm{~h}$ (higher than $97 \%$ ). Maximum removal efficiency of $99.6 \%$ was measured after $24 \mathrm{~h}$ for $\mathrm{HCH}$. The second highest efficiency of $98.9 \%$ was measured for LIN, followed by HCHB with a $97.3 \%$ removal efficiency, PCHB with a $84.8 \%$ removal efficiency and HCHBD with a $72.7 \%$. Lower affinity of the pesticides to nZVI is evident in case of HCHBD and PCHB even after $24 \mathrm{~h}$ of the treatment. The highest removal rate observed for PCHB suggests the possibility of process optimization and enhanced removal of this pollutant from model wastewater. This study has shown that the use of nZVI for the removal of synthetic organic substances is a promising option 
due to its easy application, high reactivity and efficiency.

\section{Acknowledgements}

This work was supported by the Slovak Research and Development Agency under the contract No. APVV-065612. The authors want to thank also for the support from the VEGA Grant 1/0859/14. This article was written also with the support of the Ministry of Education, Science, Research and Sport of the Slovak Republic within the Research and Development Operational Programme for the project "University Science Park of STU Bratislava”, ITMS 26240220084, co-funded by the European Regional Development Fund.

\section{References}

Černík M (2010) Chemicky podporované in situ sanační technologie. Vydavatelství VŠCHT Praha, ISBN: 978 80-7080-767-5

Chang M, Kang H (2009) Remediation of pyrenecontaminated soil by synthesized nanoscale zero-valent iron particles. J. Environ. Sci. Health 44, 576-582.

EU (2000) Directive 2000/60/EC of the European Parliament and of The Council of 23 October 2000 establishing a framework for community action in the field of water policy, Off. J. Eur. Communities, L $327 / 1$.

EU (2008) Directive 2008/105/EC of the European Parliament and of The Council of 16 December 2008 about environmental quality standards in the field of water policy, Off. J. Eur. Communities, L $348 / 84$
Grieger KD, Fjordbøge A, Hartmann NB, Eriksson E, Bjerg PL, Baun A (2010) Environmental benefits and risks of zero-valent iron nanoparticles (nZVI) for in situ remediation: Risk mitigation or trade-off? Journal of Contaminant Hydrology. 118 (3-4): 165-183.

Lin K, Chang N, Chuang T (2008) Fine structure characterization of zerovalentiron nanoparticles for decontamination of nitrites and nitrates inwastewater and groundwater. Sci. Technol. Adv. Mater. 9, 025015 .

Macé C, Desrocher S, Gheorghiu F, Kane A, Pupeza M, Cernik M, Kvapil P, Venkatakrishnan R, Zhang W (2006) Nanotechnology and groundwater remediation: A step forward in technology understanding. Remediation 16, 23-33.

Ritter L, Solomon KR, Forget J, Stemeroff M, O'Leary C (2001) Persistent organic pollutants (PDF). United Nations Environment Programme. Retrieved 2007-0916.

Stockholm Convention (2001) Stockholm Convention on Persistent Organic Pollutants, 23 May 2001, Stockholm.

Stockholm Convention (2009) Governments unite to stepup reduction on global DDT reliance and add nine new chemicals under international treaty. Stockholm Convention on Persistent Organic Pollutants. 9 May 2009, Geneva.

http://www.nanoiron.cz/images/stories/msds_ nanofer_25.pdf. 